\title{
Estimating the cost-effectiveness of daclatasvir + sofosbuvir versus sofosbuvir + ribavirin for patients with genotype 3 hepatitis $C$ virus
}

\author{
Phil McEwan ${ }^{1,2}$, Samantha Webster ${ }^{1 *}$, Thomas Ward ${ }^{1}$, Michael Brenner ${ }^{3}$, Anupama Kalsekar ${ }^{4}$ and Yong Yuan ${ }^{4}$
}

\begin{abstract}
Background: As treatments for chronic hepatitis $C$ are moving away from interferon-containing regimens, the most appropriate allocation of resources to higher cost, interferon-free, direct-acting antiviral (DAA) regimens needs to be assessed. Hepatitis $\mathrm{C}$ virus (HCV) genotype 3 is associated with faster disease progression and has fewer treatment options, historically, than other HCV genotypes. This analysis aims to estimate the comparative cost-effectiveness of two recently licenced interferon-free regimens for the treatment of HCV genotype 3.

Methods: Utilising a published Markov model and results of a matching-adjusted indirect comparison of recently published clinical trial data (ALLY-3 and VALENCE, respectively), 12 weeks of treatment with daclatasvir + sofosbuvir (DCV + SOF) was compared to 24 weeks of treatment with sofosbuvir + ribavirin (SOF + RBV). UK-specific model inputs were used to inform a cost-utility analysis of these regimens.

Results: In the base case analysis, DCV + SOF was found to be dominant over SOF + RBV in treatment-naïve patients, patients that had previously been treated, and patients that are intolerant to, or ineligible for, interferon-containing regimens. Given the low rates of treatment currently observed in the UK, DCV + SOF was also compared to no treatment in the interferon-ineligible/intolerant patients, and may be considered cost-effective with an incremental cost-effectiveness ratio of $£ 8817$.

Conclusions: When compared to 24 weeks of SOF + RBV, 12 weeks of treatment with DCV + SOF results in improved quality of life and reduced total costs, and therefore is likely to represent significant clinical and economic value as a treatment option for genotype $3 \mathrm{HCV}$ infection.
\end{abstract}

Keywords: Hepatitis C virus, Daclatasvir, Cost-effectiveness, Sofosbuvir

\section{Background}

Chronic hepatitis $\mathrm{C}$ is a progressive disease of the liver, affecting an estimated 214,000 people in the UK [1]. Chronic hepatitis $\mathrm{C}$ often results in the development of cirrhosis (i.e. permanent scarring), which can lead to end-stage liver disease (ESLD), and is a major risk factor for hepatocellular carcinoma (HCC) [2-5]. Rates of

\footnotetext{
*Correspondence: Samantha.webster@heor.co.uk

1 Health Economics \& Outcomes Research Ltd, 9 Oak Tree Court, Mulberry Drive, Cardiff Gate Business Park, Cardiff CF23 8RS, UK

Full list of author information is available at the end of the article
}

hepatitis C-related ESLD and HCC are rising, resulting in increased demand for transplant and increased rates of mortality [1].

Hepatitis $\mathrm{C}$ virus (HCV) subtypes 1 and 3 predominate in the UK [1]; however, HCV genotype 3 is associated with increased rate of progression to cirrhosis and liver decompensation, increased oncogenesis, and is accepted to be harder to treat than other genotypes, partially due to the limited number of therapy options [6-12]. Genotype 3 represents a significant proportion $(\sim 43 \%)$ of the infected UK population [1], hence prevention of ESLD, transplant and death in this large pool of patients is vital 
and is likely to be of value from both a public health, payer and individual perspective.

The treatment of choice, from both a clinical and patient perspective, is rapidly shifting from regimens that are interferon-based, due to efficacy (defined by a sustained virologic response [SVR] to treatment) and tolerability issues, to direct-acting antiviral (DAA) regimens, with high efficacy and good safety profiles. As such, payers are faced with difficult decisions regarding the most appropriate allocation of resources to these treatments, given their relatively high costs. Three interferon-free regimens are currently available in the UK for the treatment of $\mathrm{HCV}$ genotype 3: sofosbuvir in combination with ribavirin (SOF $+\mathrm{RBV}$ ), sofosbuvir in combination with ledipasvir (SOF + LDV) and daclatasvir in combination with sofosbuvir (DCV + SOF). Current clinical guidelines published by the European Association for the Study of the Liver (EASL) recommend the use of DCV + SOF in patients with HCV genotype 3, with treatment prioritised in patients with advanced fibrosis (i.e. those with a METAVIR score of F3-F4) [13].

The objective of this study was to investigate the costeffectiveness of DCV + SOF versus no treatment, given that treatment uptake rates are currently around $3 \%$ in the UK [1], and versus the alternative interferon-free regimen, SOF + RBV.

\section{Methods}

\section{Model}

A previously published and validated chronic hepatitis $\mathrm{C}$ Markov model was used to estimate the cost-effectiveness of interferon-free therapy regimens for treatment of HCV genotype 3 patients [14-16]. The model predicts the natural history of chronic hepatitis $\mathrm{C}$ through METAVIR fibrosis stages F0-F4 and on to ESLD complications and death (Additional file 1: Figure S1). A cohort of patients progress through METAVIR fibrosis stages F0F4 via dynamic transition rates from a meta-regression analysis of a multi-country, multi-centre study using data from 33,121 individuals chronically infected with HCV [17]. Progression to ESLD and HCV-related death were modelled using previously published static transition rates, whilst non-HCV-related mortality was estimated through the incorporation of published UK-specific life tables [18-20]. Disease transition rates are summarised in Table 1. To simulate the increased rate of disease progression observed amongst HCV genotype 3 patients, published transition rate multipliers were applied to the rates of disease progression previously described [12]. In those patients failing to achieve SVR, disease progression continues from the stage in which therapy commenced. Half-cycle corrections were applied to the models estimates of disease progression.
Table 1 Disease transition rates

\begin{tabular}{llll}
\hline Transition & Mean & SE & Sources \\
\hline F0 to F1 & 0.084 & NA & {$[17]$} \\
F1 to F2 & 0.092 & NA & \\
F2 to F3 & 0.145 & NA & \\
F3 to F4 & 0.116 & NA & \\
F4 (compensated cirrhosis) to & 0.039 & 0.010 & [20] \\
decompensated cirrhosis & & & \\
F4 (compensated cirrhosis) to HCC & 0.014 & 0.010 & \\
Decompensated cirrhosis to HCC & 0.014 & 0.010 & \\
Decompensated cirrhosis to liver transplant & 0.030 & 0.012 & \\
Decompensated cirrhosis to death & 0.130 & 0.010 & \\
HCC to liver transplant & 0.030 & 0.012 & \\
HCC to death & 0.430 & 0.030 & \\
Liver transplant (year 1) to death & 0.210 & 0.046 & \\
Liver transplant (year 2+) to death & 0.057 & 0.012 &
\end{tabular}

HCC hepatocellular carcinoma, NA not applicable, SE standard error

Each health state within the model is associated with a particular cost and health utility estimate, as presented in Table 2. All values utilised within the model are consistent with a published systematic literature review, which have been used extensively in previous economic evaluations [21-23]. All costs were inflated to 2013 values using

Table 2 Summary of health state cost and utility inputs

\begin{tabular}{|c|c|c|c|}
\hline Health state & $\begin{array}{l}\text { Cost }(2012 / 13 £) \\
\text { Mean (SE) }\end{array}$ & $\begin{array}{l}\text { Utility } \\
\text { Mean (SE) }\end{array}$ & Source \\
\hline \multicolumn{4}{|l|}{ Fibrosis stages } \\
\hline FO & $177.47(35.01)$ & $0.77(0.015)$ & {$[21]$} \\
\hline $\mathrm{F} 1$ & $177.47(35.01)$ & $0.77(0.015)$ & \\
\hline $\mathrm{F} 2$ & $922.08(97.82)$ & $0.66(0.031)$ & \\
\hline F3 & $922.08(97.82)$ & $0.66(0.031)$ & \\
\hline F4 (compensated cirrhosis) & $1463.50(297.45)$ & $0.55(0.054)$ & \\
\hline \multicolumn{4}{|l|}{ SVR } \\
\hline SVR from F0 to F1 & $333.08(62.05)$ & $0.82(0.043)$ & {$[21]$} \\
\hline SVR from F2 to F3 & $922.08(97.74)$ & $0.72(0.048)$ & \\
\hline $\begin{array}{l}\text { SVR from F4 (compensated } \\
\text { cirrhosis) }\end{array}$ & $1463.50(288.07)$ & $0.72(0.048)^{a}$ & \\
\hline \multicolumn{4}{|l|}{ ESLD } \\
\hline Decompensated cirrhosis & $11,728.61$ (1954.09) & $0.45(0.031)$ & {$[21]$} \\
\hline $\mathrm{HCC}$ & $10,451.58(2456.09)$ & $0.45(0.031)$ & \\
\hline $\begin{array}{l}\text { Liver transplant (transplant } \\
\text { cost) }\end{array}$ & $35,147.26(3709.93)$ & NA & \\
\hline $\begin{array}{l}\text { Liver transplant (cost of } \\
\text { care: initial year) }\end{array}$ & $12,163.29(3133.55)$ & $0.45(0.031)$ & \\
\hline $\begin{array}{l}\text { Liver transplant (subse- } \\
\text { quent years) }\end{array}$ & $1781.15(456.57)$ & $0.67(0.066)$ & \\
\hline
\end{tabular}

HCC hepatocellular carcinoma, NA not applicable, SE standard error, SVR sustained virologic response, ESLD end stage liver disease

assumption, based on SVR from F2 to F3 
the Hospital and Community Health Services index, where required [24]. Costs and health utility estimates were discounted annually at a rate of $3.5 \%$, in line with UK guidelines [25]. Total costs and quality-adjusted life years (QALYs) associated with each treatment regimen are accumulated over the modelled time horizon and used to predict the cost-effectiveness of each comparison.

For this analysis, since there is a paucity of robust epidemiology data, patients within the modelled cohort were assumed to be evenly distributed across fibrosis stages F0-F4 at initiation. A mean age of 50 years was applied, of which $67 \%$ were male, according to UK estimates [26-28]. The cohort was modelled over a lifetime horizon, assuming a maximum age of 100 years. It was assumed that the progression of disease is halted following SVR, regardless of fibrosis stage at therapy initiation.

\section{Treatment}

Treatment with DCV + SOF was compared to SOF + RBV in three patient populations; treatmentnaïve, treatment-experienced and interferon-ineligible/ intolerant. To provide economic context for the potential consideration of not treating patients who may be more difficult to treat, an additional comparison against "no treatment" was undertaken in interferon-ineligible/ intolerant patients. As direct comparative data were not available for the treatment regimens under investigation, an indirect comparison of efficacy and safety observed in the ALLY-3 (NCT02032901) and VALENCE (NCT01682720) phase III clinical trials of DCV + SOF and SOF + RBV, respectively, was carried out via the matching-adjusted indirect comparison (MAIC) method $[29,30]$. MAIC data were available for DCV + SOF and SOF + RBV in the treatment-naïve and treatmentexperienced patient populations [31]. However, as no data specific to the interferon-ineligible/intolerant population were identified for the SOF + RBV regimen, it was assumed that the efficacy in this subgroup was equivalent to the SVR in the pooled naïve and experienced subgroups since this subgroup would inherently comprise patients that have not received treatment (due to contraindications) or have received treatment, but discontinued (due to tolerability). Treatment-related model inputs are detailed in Table 3.

Unit costs of treatments were sourced from the Monthly Index of Medical Specialities (MIMS) and regimen durations were modelled according to EASL guidelines and trials used [2, 29,30]. Due to their relative infrequency, costs relating to treatment-related adverse events and discontinuations were not modelled; however, regimen-specific disutilities were applied for the duration of therapy (Table 3). As data relating to the costs of monitoring patients receiving new DAA therapies are not yet available, monitoring costs consistent with previous health technology assessments of pegylated interferonalpha-based regimens were utilised [20].

\section{Analysis}

The analysis was performed from the perspective of the UK NHS and personal social services. Base case analysis compared total costs and QALYs of each regimen and estimated the incremental cost-effectiveness ratio (ICER) for each comparison.

One-way sensitivity analyses were undertaken in order to assess the impact of individual parameters on cost-effectiveness, whilst probabilistic sensitivity analysis (PSA) was undertaken to assess the uncertainty surrounding model input parameters. Static transition rates, proportions and utilities were sampled from beta distributions, age and coefficients of the dynamic transition rates from normal distributions and costs from gamma distributions.

Table 3 Treatment-related model inputs

\begin{tabular}{|c|c|c|c|c|c|c|c|c|}
\hline \multirow[t]{2}{*}{ Regimen } & \multirow{2}{*}{$\begin{array}{l}\text { Duration } \\
\text { (weeks) }\end{array}$} & \multicolumn{2}{|c|}{ Acquisition cost } & \multicolumn{3}{|l|}{ SVR } & \multicolumn{2}{|c|}{ Disutility } \\
\hline & & Per week (£) & Source & Population & $\%$ & Source & Mean & Source \\
\hline \multirow[t]{3}{*}{$\mathrm{DCV}+\mathrm{SOF}$} & \multirow[t]{3}{*}{12} & \multirow[t]{3}{*}{4958.37} & \multirow{3}{*}{$\begin{array}{l}\text { Monthly index of } \\
\text { medical specialities }\end{array}$} & Treatment-naïve & 96.4 & \multirow[t]{3}{*}{ MAIC [30] } & \multirow[t]{3}{*}{0.035} & \multirow[t]{3}{*}{ Estimated from [37 } \\
\hline & & & & Treatment-experienced & 83.2 & & & \\
\hline & & & & $\begin{array}{l}\text { Interferon-ineligible/ } \\
\text { intolerant }\end{array}$ & $88.8^{\mathrm{a}}$ & & & \\
\hline \multirow[t]{3}{*}{$\mathrm{SOF}+\mathrm{RBV}$} & \multirow[t]{3}{*}{24} & \multirow[t]{3}{*}{2982.19} & \multirow{3}{*}{$\begin{array}{l}\text { Monthly index of } \\
\text { medical specialities }\end{array}$} & Treatment-naïve & 94.3 & \multirow[t]{3}{*}{$\operatorname{MAIC}[30]$} & \multirow[t]{3}{*}{0.048} & \multirow[t]{3}{*}{ Estimated from [38] } \\
\hline & & & & Treatment-experienced & 78.6 & & & \\
\hline & & & & $\begin{array}{l}\text { Interferon-ineligible/ } \\
\text { intolerant }\end{array}$ & $85.2^{a}$ & & & \\
\hline No treatment & NA & 0 & NA & $\begin{array}{l}\text { Interferon-ineligible/ } \\
\text { intolerant }\end{array}$ & 0 & Assumed & 0 & NA \\
\hline
\end{tabular}

DCV daclatasvir, NA not applicable, MAIC matching-adjusted indirect comparison, RBV ribavirin, SOF sofosbuvir, SVR sustained virologic response

a Assumed, based on pooled treatment-naïve and treatment-experienced subgroups 
To address uncertainty surrounding rates of SVR, an exploratory analysis was undertaken to estimate the minimum rate of SVR of the DCV + SOF regimen such that it would remain cost-effective at the $£ 20,000 / Q A L Y$ threshold [32].

\section{Results}

\section{Base case analysis}

The base case analysis demonstrates that DCV + SOF is cost-effective against SOF $+\mathrm{RBV}$ in all comparisons tested: treating with $\mathrm{DCV}+\mathrm{SOF}$ was predicted to result in total cost savings of $£ 12,647, £ 13,426$ and $£ 12,305$ in treatment-naïve, treatment-experienced and interferonineligible/intolerant populations respectively. Predicted QALY-gains were $0.118,0.219$ and 0.165 respectively, resulting in $\mathrm{DCV}+\mathrm{SOF}$ dominating $\mathrm{SOF}+\mathrm{RBV}$ in all comparisons. When comparing to no treatment in the interferon-ineligible/intolerant population, $\mathrm{DCV}+\mathrm{SOF}$ was predicted to give rise to an incremental cost of $£ 32,476$, with a QALY gain of 3.683 . The associated ICER estimate was $£ 8817$, which is cost-effective at the $£ 20,000 /$ QALY threshold (Table 4).

\section{Sensitivity analyses}

Univariate sensitivity analyses demonstrated that the cost-effectiveness is most sensitive to assumptions surrounding discounting, patient age and model time horizon (Fig. 1). Using a model time horizon of 20 years decreases expected cost-effectiveness; however, no conclusions changed. Increasing rates of annual discounting resulted in reduced cost-effectiveness, whilst decreasing the rate resulted in improved cost-effectiveness. A similar trend was observed when increasing and decreasing age.

PSA demonstrated that all comparisons have a $100 \%$ probability of cost-effectiveness when parameter uncertainty was taken into consideration, with all individual PSA simulations resulting in cost-effective results, across all scenarios.

\section{Exploratory efficacy analysis}

Analysis undertaken to estimate the possible reduction in $\mathrm{DCV}+\mathrm{SOF}$ SVR rates at which the regimen is no longer expected to be cost-effective predicted that the SVR rate of DCV + SOF could be reduced by $13.1 \%, 15.6 \%$ and $13.6 \%$, amongst treatment-naïve, treatment-experienced and interferon-ineligible/intolerant patients respectively before the regimen is no longer expected to be cost-effective against SOF $+\mathrm{RBV}$ at the lower cost-effectiveness threshold of $£ 20,000 / Q A L Y$. Similarly, it was predicted that the SVR of DCV + SOF could be reduced by $26.0 \%$, when compared to no treatment, before it is no longer expected to be cost-effective (Table 4).

\section{Discussion}

Since an estimated 92,000 individuals, almost half the $\mathrm{HCV}$-infected population, have genotype 3 in the UK, there is a clear need to provide clinical and cost-effective treatment options for this considerable pool of patients [1]. Presented is the first cost-effectiveness analysis of two interferon-free regimens for the treatment of $\mathrm{HCV}$ genotype 3 in a UK context. The results of this analysis demonstrate the significant value that is expected to be realised by the use of 12 weeks of DCV + SOF over 24 weeks of SOF + RBV or no treatment. These conclusions are consistent with a published cost-effectiveness analysis in the Italian setting [33].

Considering the cost savings estimated, a lower overall budget impact is expected via the adoption of $\mathrm{DCV}+\mathrm{SOF}$ over SOF + RBV. Cost-savings and QALY gains for the DCV + SOF regimen are largely driven by the shorter treatment duration, higher SVRs and the resulting avoidance of high cost ESLD complications.

These are important findings, given that there are currently few treatment options for HCV genotype 3, especially considering the high proportion of patients that cannot tolerate, are not recommended to receive or are unwilling to take an interferon-containing regimen, estimated at $67.0-83.5 \%$ of infected patients [34, 35]. Furthermore, EASL clinical guidelines recommend $\mathrm{DCV}+\mathrm{SOF}$ in patients with HCV genotype 3 due to the suboptimal efficacy of the SOF + RBV regimen [13].

Given the rapidly developing nature of the field, challenges exist in comparing novel regimens. To inform this analysis, an indirect comparison was performed in an attempt to eliminate bias that may have been observed via a naïe comparison of the raw trial data; however, in the absence of direct head-to-head data, some uncertainty remains. Furthermore, due to the unavailability of data specifically for interferon-ineligible/intolerant patients for either DCV + SOF or SOF + RBV, an assumed SVR, taking the entire patient population (treatment-naïve and -experienced patients) of the trials into consideration, has been used. It is uncertain whether this will under- or over-estimate costs and QALYs in this population; however, a consistent approach has been applied to both regimens. Despite uncertainties in the data, SVR threshold analysis gives confidence in the level by which the SVR of $\mathrm{DCV}+\mathrm{SOF}$ can fall to no longer be cost effective versus both SOF + RBV and no treatment (8.5-28.6\% reduction in SVR, depending on the scenario).

It has previously been demonstrated that disease progression in patients with genotype $3 \mathrm{HCV}$ infection occurs faster than that of other genotypes [6-12]. However, with respect to the modelling of HCV genotype 3 , genotype-specific disease state transition rates are unavailable, with economic models relying on the use 


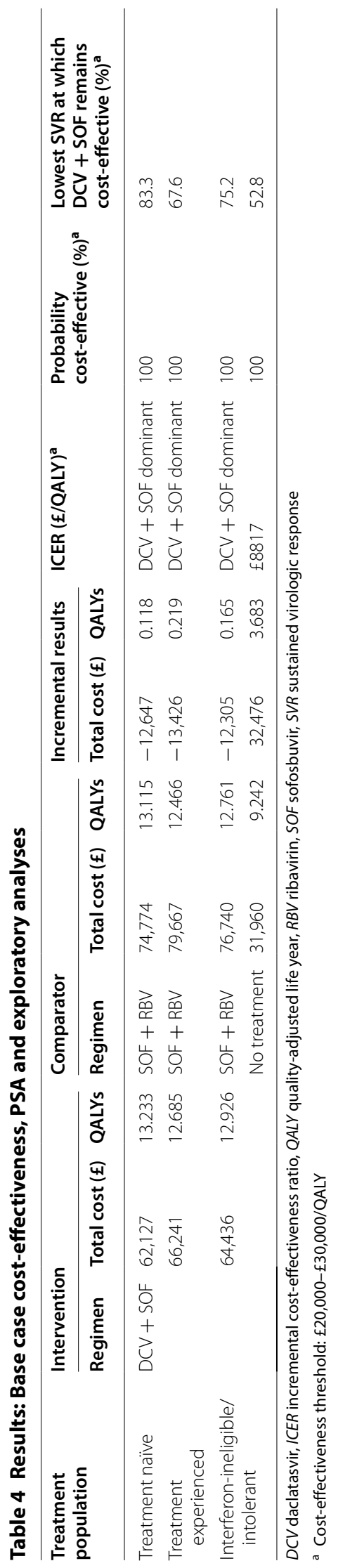




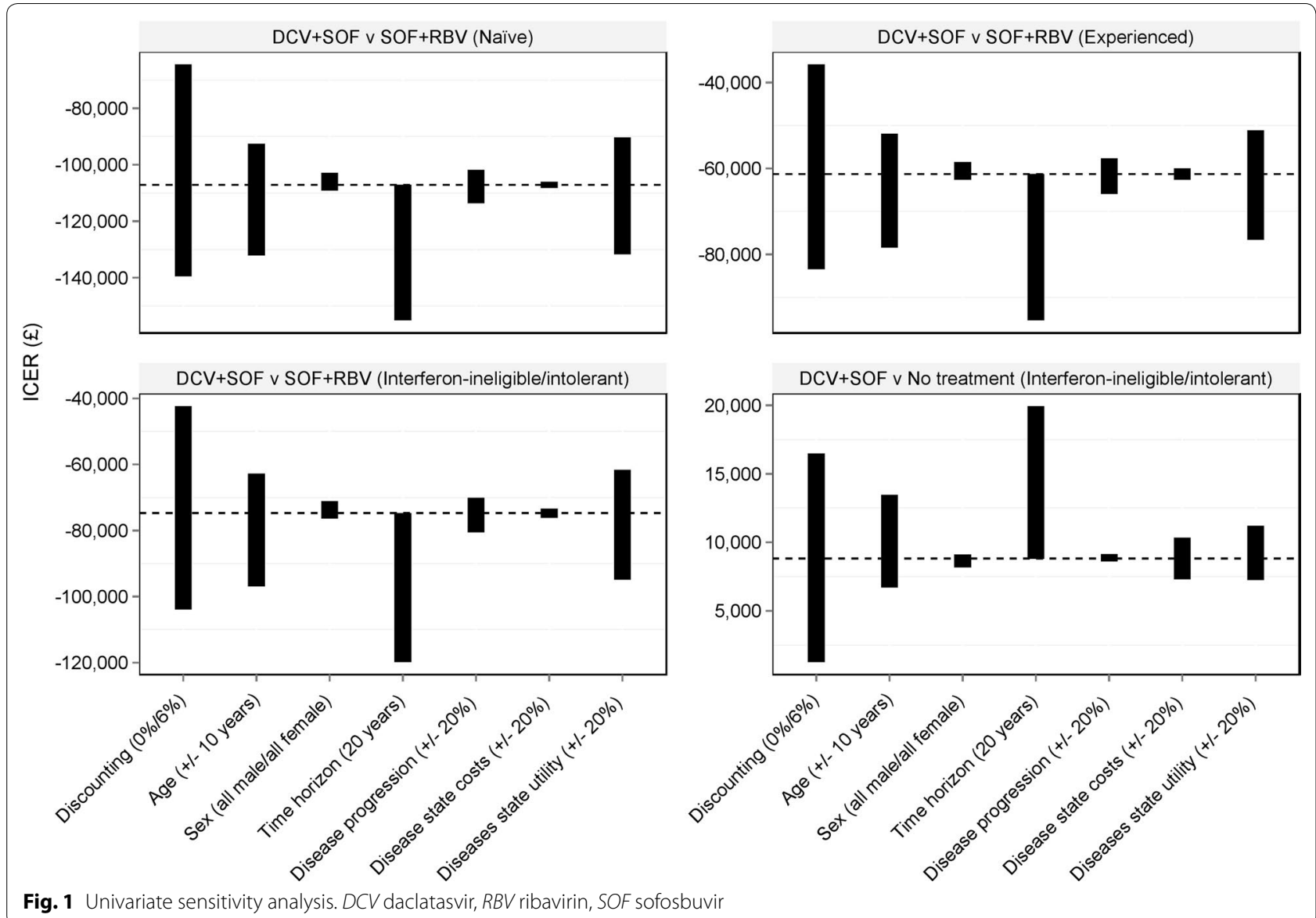

of transition rate multipliers applied to disease progression rates of a genotype 1 population. Therefore, further research into the patterns of disease progression of $\mathrm{HCV}$ genotype 3 patients may be warranted to more accurately predict the disease progression of such patients. In addition, it was assumed that the progression of disease is halted following SVR, regardless of fibrosis stage at therapy initiation. There is some evidence to suggest that disease may progress after SVR [36, 37]; however, this rate is very low ( $\sim 1 \%$ progress to cirrhosis) and is not expected to meaningfully impact cost-effectiveness results [37].

$\mathrm{DCV}+$ SOF provides a short, safe and effective treatment option for $\mathrm{HCV}$ genotype 3 patients. Considering that the majority of infections occur via injecting drug use, there is evidence to suggest that the introduction of novel DAA regimens offers the opportunity to decrease onward transmission of $\mathrm{HCV}$ [38], considering their improved efficacy and tolerability, with reduced time on treatment, compared to historical treatments. This means that a conventional cost-effectiveness evaluation, as presented here, is likely to underestimate the benefit, and therefore value, of treatment. Furthermore, this analysis assumed equal distribution of patients across fibrosis stages F0-F4; given the findings of previous economic analyses in chronic hepatitis $C$, there is likely to be higher value in taking a targeted approach to treatment, i.e. prioritising treatment in those with most advanced disease ( $\geq F$ 3), before the development of ESLD complications.

In this continually evolving field, there is emerging preference for interferon-free regimens from both the patient and clinician perspective. Currently, as well as $\mathrm{DCV}+\mathrm{SOF}$ and SOF + RBV, a third interferon-free regimen (SOF + LDV) is available in the UK for treating $\mathrm{HCV}$ genotype 3; this regimen has recently received marketing authorisation; however, data for this regimen are very limited in $\mathrm{HCV}$ genotype 3 and are restricted to a regimen duration that is not within the marketing authorisation [39]. Therefore, a reliable comparative analysis could not be undertaken. Future analyses should incorporate this regimen, when more data are available. However, it should be noted that recent clinical guidelines recommend only the $\mathrm{DCV}+\mathrm{SOF}$ regimen in patients with HCV genotype 3, as LDV has been 
demonstrated to be considerably less potent against genotype 3 than DCV in vitro [13].

\section{Conclusions}

This is the first empirical analysis of contemporary clinical data describing the comparative cost-effectiveness of DCV + SOF versus SOF + RBV and no treatment in patients with HCV genotype 3. DCV + SOF was found to be dominant against SOF + RBV at established norms among treatment-naive and -experienced patients, and patients who are interferon-intolerant or ineligible. Results were robust across alternative values for key input parameters.

\section{Additional file}

Additional file 1: Figure S1. Schematic of the cohort-based Markov simulation model.

\section{Abbreviations}

DAA: direct-acting antiviral; HCV: hepatitis C virus; DCV: daclatasvir; SOF: sofosbuvir; RBV: ribavirin; ESLD: end-stage liver disease; HCC: hepatocellular carcinoma; SVR: sustained virologic response; EASL: European Association for the Study of the Liver; LDV: ledipasvir; QALY: quality-adjusted life year; MAIC: matchingadjusted indirect comparison; ICER: incremental cost-effectiveness ratio; PSA: probabilistic sensitivity analysis; MIMS: Monthly Index of Medical Specialities.

\section{Authors' contributions}

All authors are responsible for the reported research, and have participated in the concept and design, analysis and interpretation of data, drafting or revising of the article. All authors read and approved the final manuscript.

\section{Author details}

${ }^{1}$ Health Economics \& Outcomes Research Ltd, 9 Oak Tree Court, Mulberry Drive, Cardiff Gate Business Park, Cardiff CF23 8RS, UK. ${ }^{2}$ School of Human \& Health Sciences, Swansea University, Swansea, UK. ${ }^{3}$ UK HEOR, Bristol-Myers Squibb Pharmaceuticals Ltd, Uxbridge, UK. ${ }^{4}$ World Wide Health Economics and Outcomes Research, Bristol-Myers Squibb Pharmaceuticals Ltd, Princeton, USA

\section{Competing interests}

Phil McEwan, Thomas Ward and Samantha Webster are employees of Health Economics and Outcomes Research Ltd, who received funding from BristolMyers Squibb Pharmaceuticals Ltd for analyses and writing. Michael Brenner, Anupama Kalsekar and Yong Yuan are employees of the sponsor.

\section{Availability of data and materials}

The model used in this analysis is proprietary; however, all data used are publicly available.

\section{Funding}

Funding for research and writing was provided by Bristol-Myers Squibb Pharmaceuticals Ltd. The publication of study results was not contingent on the sponsor's approval or censorship of the manuscript.

\section{Publisher's Note}

Springer Nature remains neutral with regard to jurisdictional claims in published maps and institutional affiliations.

Received: 12 May 2016 Accepted: 14 July 2017

Published online: 21 July 2017

\section{References}

1. Public Health England, Health Protection Scotland, Public Health Wales, Public Health Agency. Hepatitis C in the UK: 2014 report. 2014. https:// www.gov.uk/government/uploads/system/uploads/attachment_data/ file/337115/HCV_in_the_UK_2014_24_July.pdf. Accessed Jan 2015.

2. European Association for the Study of the Liver. EASL recommendations on treatment of hepatitis C. 2014. http://files.easl.eu/easl-recommendations-on-treatment-of-hepatitis-C.pdf. Accessed Sep 2014.

3. World Health Organization. Guidelines for the screening, care and treatment of persons with hepatitis C infection. 2014 http://www.who.int/hiv/ pub/hepatitis/hepatitis-c-guidelines/en/. Accessed Jan 2015.

4. Kanwal F, Hoang T, Kramer JR, Asch SM, Goetz MB, Zeringue A, et al. Increasing prevalence of HCC and Cirrhosis in patients with chronic hepatitis C virus infection. Gastroenterology. 2010;140(4):1182-8.

5. de Oliveria Andrade $\sqcup$, D'Oliveira A, Melo RC, De Souza EC, Costa Silva CA, Paraná R. Association between hepatitis $C$ and hepatocellular carcinoma. J Glob Infect Dis. 2009;1(1):33-7.

6. Bochud PY, Cai T, Overbeck K, Bochud M, Dufour JF, Mullhaupt B, et al. Genotype 3 is associated with accelerated fibrosis progression in chronic hepatitis C. J Hepatol. 2009;51(4):655-66.

7. Probst A, Dang T, Bochud M, Egger M, Negro F, Bochud PY. Role of hepatitis $C$ virus genotype 3 in liver fibrosis progression-a systematic review and meta-analysis. J Viral Hepat. 2011;18(11):745-59.

8. McMahon BJ, Bruden D, Bruce MG, Livingston S, Christensen C, Homan $C$, et al. Adverse outcomes in Alaska natives who recovered from or have chronic hepatitis C infection. Gastroenterology. 2010;138(3):922-31.

9. Larsen C, Bousquet V, Delarocque-Astagneau E, Pioche C, RoudotThoraval F, Desenclos JC. Hepatitis C virus genotype 3 and the risk of severe liver disease in a large population of drug users in France. J Med Virol. 2010;82(10):1647-54.

10. van der Meer AJ, Veldt BJ, Feld JJ, Wedemeyer H, Dufour JF, Lammert F, et al. Association between sustained virological response and all-cause mortality among patients with chronic hepatitis $C$ and advanced hepatic fibrosis. JAMA. 2012;308(24):2584-93.

11. Nkontchou G, Ziol M, Aout M, Lhabadie M, Baazia Y, Mahmoudi A, et al. HCV genotype 3 is associated with a higher hepatocellular carcinoma incidence in patients with ongoing viral C cirrhosis. J Viral Hepat. 2011;18(10):e516-22

12. Kanwal F, Kramer JR, Ilyas J, Duan Z, El-Serag HB. HCV genotype 3 is associated with an increased risk of cirrhosis and hepatocellular cancer in a national sample of US Veterans with HCV. Hepatology. 2014;60(1):98-105.

13. European Association for the Study of the Liver. EASL recommendations on treatment of hepatitis C 2015. J Hepatol. 2015;63:199.

14. McEwan P, Kim R, Yuan Y. Assessing the cost utility of response-guided therapy in patients with chronic hepatitis $C$ genotype 1 in the UK using the MONARCH model. Appl Health Econ Health Policy. 2013;11(1):53-63.

15. McEwan P, Ward T, Yuan Y, Kim R, L'Italien G. The impact of timing and prioritization on the cost-effectiveness of birth cohort testing and treatment for hepatitis $C$ virus in the United States. Hepatology (Baltimore, Md). 2013;58(1):54-64.

16. McEwan $\mathrm{P}$, Ward T, Chen C-J, Lee M-H, Yang H-I, Kim R, et al. Estimating the incidence and prevalence of chronic hepatitis $C$ infection in Taiwan using back projection. Value Health Reg Issues. 2014:3:5-11.

17. Thein HH, Yi Q, Dore GJ, Krahn MD. Estimation of stage-specific fibrosis progression rates in chronic hepatitis $C$ virus infection: a meta-analysis and meta-regression. Hepatology. 2008;48(2):418-31.

18. Office of National Statistics. National life tables, 2010-2012: UK reference tables 2013. 2014. http://www.ons.gov.uk/ons/publications/re-referencetables.html?edition=tcm\%3A77-325699. Accessed 14 Oct 2014.

19. Office of National Statistics. Mortality statistics: deaths registered in England and Wales (Series DR). 2012, 2013. http://www.ons.gov.uk/ons/publications/ re-reference-tables.html?edition=tcm\%3A77-325289. Accessed Jan 2015.

20. Shepherd J, Jones J, Hartwell D, Davidson P, Price A, Waugh N. Interferon alpha (pegylated and non-pegylated) and ribavirin for the treatment of mild chronic hepatitis C: a systematic review and economic evaluation. Health Technol Assess (Winchester, England). 2007:11(11):1-205.

21. Martin NK, Vickerman P, Miners A, Foster GR, Hutchinson SJ, Goldberg DJ, et al. Cost-effectiveness of hepatitis $C$ virus antiviral treatment for injection drug user populations. Hepatology. 2012;55(1):49-57. 
22. Townsend R, McEwan P, Kim R, Yuan Y. Structural frameworks and key model parameters in cost-effectiveness analyses for current and future treatments of chronic hepatitis C. Value Health. 2011;14(8):1068-77.

23. Janssen $L t d$. Telaprevir for the treatment of genotype 1 chronic hepatitis C. High Wycombe: Janssen Ltd; 2011.

24. Personal Social Services Research Unit. Unit costs of health and social care 2013. Section 16.2: The hospital \& community health services (HCHS) index; 2013.

25. National Institute for Health and Care Excellence. Guide to the methods of technology appraisal 2013. 2013. http://www.nice.org.uk/article/pmg9. Accessed 24 Nov 2015.

26. Public Health England. Commissioning template for estimating HCV prevalence by DAT and numbers eligible for treatment. 2014. http:// www.hpa.org.uk/Topics/InfectiousDiseases/InfectionsAZ/HepatitisC/EpidemiologicalData/. Accessed Jul 2014.

27. Public Health England, Health Protection Scotland, Public Health Wales, Public Health Agency. Hepatitis C in the UK: 2013 report. 2013. http:// www.hpa.org.uk/Publications/InfectiousDiseases/BloodBornelnfections/ HepatitisCInTheUK/1307HepatitisCintheUK2013report/. Accessed Jun 2014.

28. Nottingham University Hospitals NHS Trust, Medical Research Foundation. Host and viral factors associated with outcomes of infection with hepatitis C virus (HCV Research UK). Nottingham: Nottingham University Hospitals NHS Trust; 2014.

29. Nelson DR, Cooper JN, Lalezari JP, Lawitz E, Pockros PJ, Gitlin N, et al. Alloral 12-week treatment with daclatasvir plus sofosbuvir in patients with hepatitis C virus genotype 3 infection: ALLY-3 phase 3 study. Hepatology. 2015;61:1127-35.

30. Zeuzem S, Dusheiko GM, Salupere R, Mangia A, Flisiak R, Hyland RH, et al. Sofosbuvir and ribavirin in HCV genotypes 2 and 3. N Engl J Med. 2014;370(21):1993-2001.

31. Swallow E. Comparative efficacy and tolerability of daclatasvir + sofosbuvir versus sofosbuvir + ribavirin for hepatitis C genotype 3: a matching-adjusted indirect comparison. Vienna: The International Liver Congress; 2015

32. National Institute for Health and Care Excellence. Judging whether public health interventions offer value for money. Local government briefing [LGB10]. 2013. https://www.nice.org.uk/advice/lgb10/chapter/judgingthe-cost-effectiveness-of-public-health-activities. Accessed 13 Mar 2017.

33. Restelli U, Alberti A, Lazzarin A, Bonfanti M, Nappi C, Croce D. Costeffectiveness analysis of the use of daclatasvir + sofosbuvir + ribavirin (16 weeks and 12 weeks) vs sofosbuvir + ribavirin (16 weeks and 24 weeks) for the treatment of cirrhotic patients affected with hepatitis C virus genotype 3 in Italy. Eur J Health Econ. 2016. pp. 1-8. doi:10.1007/ s10198-016-0865-3.

34. Crespo J, Cabezas J, Sacristán B, Olcoz JL, Pérez R, De la Vega J, et al. Barriers to HCV treatment in the era of triple therapy: a prospective multicentred study in clinical practice. Liver Int. 2015;35(2):401-8.

35. Kramer JR, Kanwal F, Richardson P, Mei M, El-Serag HB. Gaps in the achievement of effectiveness of HCV treatment in national VA practice. J Hepatol. 2011;56(2):320-5.

36. Lee YA, Friedman SL. Reversal, maintenance or progression: what happens to the liver after a virologic cure of hepatitis C? Antivir Res. 2014;107:23-30.

37. Poynard T, Moussalli J, Munteanu M, Thabut D, Lebray P, Rudler M, et al. Slow regression of liver fibrosis presumed by repeated biomarkers after virological cure in patients with chronic hepatitis C. J Hepatol. 2013;59(4):675-83.

38. Martin NK, Vickerman P, Grebely J, Hellard M, Hutchinson SJ, Lima VD, et al. Hepatitis $C$ virus treatment for prevention among people who inject drugs: modeling treatment scale-up in the age of direct-acting antivirals. Hepatology. 2013;58(5):1598-609.

39. Gilead Sciences International Ltd. Summary of product characteristics. Harvoni 90 mg/400 mg film-coated tablets. 2015. https://www.medicines.org.uk/emc/medicine/29471. Accessed Mar 2015.

\section{Submit your next manuscript to BioMed Central and we will help you at every step:}

- We accept pre-submission inquiries

- Our selector tool helps you to find the most relevant journal

- We provide round the clock customer support

- Convenient online submission

- Thorough peer review

- Inclusion in PubMed and all major indexing services

- Maximum visibility for your research

Submit your manuscript at www.biomedcentral.com/submit 